\title{
Extracellular matrix composition in COPD
}

\author{
Raquel Annoni*, Tatiana Lanças*, Ryan Yukimatsu Tanigawa*, \\ Marcus de Medeiros Matsushita*, Sandra de Morais Fernezlian*, Andreina Bruno", \\ Luiz Fernando Ferraz da Silva*, Peter J. Roughley+, Salvatore Battaglia ${ }^{\S}$, \\ Marisa Dolhnikoff*, Pieter S. Hiemstra ${ }^{f}$, Peter J. Sterk**, \\ Klaus F. Rabe ${ }^{\# \#}$ and Thais Mauad*
}

ABSTRACT: Extracellular matrix (ECM) composition has an important role in determining airway structure. We postulated that ECM lung composition of chronic obstructive pulmonary disease (COPD) patients differs from that observed in smoking and nonsmoking subjects without airflow obstruction.

We determined the fractional areas of elastic fibres, type-I, -III and -IV collagen, versican, decorin, biglycan, lumican, fibronectin and tenascin in different compartments of the large and small airways and lung parenchyma in 26 COPD patients, 26 smokers without COPD and 16 nonsmoking control subjects.

The fractional area of elastic fibres was higher in non-obstructed smokers than in COPD and nonsmoking controls, in all lung compartments. Type-I collagen fractional area was lower in the large and small airways of COPD patients and in the small airways of non-obstructed smokers than in nonsmokers. Compared with nonsmokers, COPD patients had lower versican fractional area in the parenchyma, higher fibronectin fractional area in small airways and higher tenascin fractional area in large and small airways compartments. In COPD patients, significant correlations were found between elastic fibres and fibronectin and lung function parameters.

Alterations of the major ECM components are widespread in all lung compartments of patients with COPD and may contribute to persistent airflow obstruction.

KEYWORDS: Chronic obstructive pulmonary disease, cigarette smoking, extracellular matrix, pathology, respiratory function tests

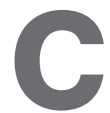
hronic obstructive pulmonary disease (COPD) is a leading cause of mortality and morbidity worldwide. Its burden is still underestimated as COPD is under-diagnosed and under treated in high- and low-income countries, mainly in the mild stages of the disease [1-3]. Smoking is the most important risk factor for the development of COPD. It has been proposed that the chronic cigarette-induced inflammation is associated with the development of structural changes in the lungs of susceptible smokers, which contribute to progressive airflow limitation $[4,5]$.

The major lung extracellular matrix (ECM) components are collagens, elastic fibres, proteoglycans, fibronectin and tenascin [6, 7]. Previous studies have reported a decrease of elastin [8-10] and proteoglycans [11] and an increase of total collagen content in the alveoli of COPD patients [12]. Few studies have assessed ECM composition at different levels of the airways and lung parenchyma $[13,14]$.
Collagens are the most abundant components of the lung interstitium and, particularly the fibrillar type-I and -III collagens, are important in maintaining the lung architecture. Type-IV collagen is the main constituent of basement membranes and the most abundant non-fibrillar collagen in the lungs $[15,16]$.

Proteoglycans are macromolecules composed of a protein core and glycosaminoglycan side chains that are involved in maintaining the assembly of collagen fibrils, water balance and cell adhesion and migration [17, 18]. Little is known about the pattern of proteoglycans deposition in the lungs of COPD patients. So far, studies described alterations of versican and decorin in the distal lung $[10,11]$.

Tenascin and fibronectin are altered in ongoing tissue injury, regulating important cell properties and inflammatory cell chemotaxis [19]. There are few studies analysing the expression of tenascin
AFFILIATIONS

*Dept of Pathology, University of São Paulo Medical School, São Paulo, and

\#University of Marilia Medical

School, Marilia, Brazil

"Institute of Biomedicine and Molecular Immunology (IBIM), Consiglio Nazionale delle Ricerche (CNR), and

${ }^{\S}$ Dipartimento Biomedico di Medicina Interna e Specialistica (Di.Bi.MIS), University of Palermo, Palermo, Italy.

+Shriners Hospital for Children, McGill University, Montreal, QC Canada.

${ }^{\dagger}$ Dept of Pulmonology, Leiden University Medical Center, Leiden, and

${ }^{*}$ Dept of Respiratory Medicine, Academic Medical Centre, University of Amsterdam, Amsterdam, The Netherlands.

\#\#Dept of Medicine, University of Kiel, Kiel, Germany.

CORRESPONDENCE

R. Annoni

São Paulo University Medical School

Av. Dr. Arnaldo 455/Room 1155

São Paulo 01246-903

Brazil

E-mail: rqannoni@yahoo.com.br

Received:

Nov 042011

Accepted after revision:

March 152012

First published online:

April 102012

Online ISSN 1399-3003 
and fibronectin in COPD patients [13,20,21], but no study has addressed these proteins in all lung compartments.

We hypothesised that the composition of ECM is different in the large airways, small airways and lung parenchyma and between patients with COPD and smokers and nonsmokers with normal lung function. Furthermore, we hypothesised that such differences contribute to lung function impairment in COPD.

Therefore, our aim was to quantify the composition of several ECM components (elastic fibres, type-I, -III and -IV collagen, versican, decorin, biglycan, lumican, fibronectin and tenascin) in all lung compartments of patients with COPD, in relation to cigarette smoking and lung function.

\section{METHODS}

This study was approved by the review board of the São Paulo University Medical School and A.C. Camargo Hospital (both São Paulo, Brazil), Leiden University Medical Centre (Leiden, the Netherlands) and Palermo University (Palermo, Italy). All subjects provided written informed consent.

\section{Subjects}

We analysed lung tissue collected from 68 patients undergoing lung resection surgery for primary or metastatic lung tumours from 2001 to 2007.

Information including demographic data, medical and smoking history, medications and pre-operative lung function was obtained from the patients' hospital charts. Patients with a diagnosis of asthma, bronchiectasis, infectious diseases, $\alpha_{1-}$ antitrypsin deficiency or interstitial lung disease were not included.

Patients were classified as follows. 1) Nonsmokers (NS, $n=16$ ); never-smokers, forced expiratory volume in $1 \mathrm{~s}$ (FEV1) $\geqslant 80 \%$ predicted and FEV1/forced vital capacity (FVC) $\geqslant 70 \%$. 2) Nonobstructed smokers (NOS, $\mathrm{n}=26$ ): current and/or ex-smokers (quit for $\geqslant 1$ month) with normal lung function (FEV1 $\geqslant 80 \%$ pred and FEV1/FVC $\geqslant 70 \%)$. 3) COPD ( $\mathrm{n}=26)$ : current and/or ex-smokers (quit for $\geqslant 1$ month) with COPD (FEV1/FVC $<70 \%$ ). Post-bronchodilator values were available in 15 COPD patients (five Global Initiative for Chronic Obstructive Lung Disease (GOLD) stage I, mild, nine GOLD stage II, moderate, and one GOLD stage III, severe, [1]), and all showed $<12 \%$ improvement compared with the pre-bronchodilator value.

\section{Tissue processing}

Two to four blocks of peripheral parenchyma and one or two blocks of central airways remote from the tumour were obtained in most cases. In general, less tissue was available from central areas because of tumour proximity or surgical borders. Fragments were fixed in $10 \%$ buffered formalin for $24 \mathrm{~h}$, processed and paraffin embedded. $4-\mu \mathrm{m}$ thick sections were stained with haematoxylin-eosin for initial analysis. We excluded cases showing fibrotic disorders, neoplastic tissue and post-stenotic pneumonia.

\section{Histochemistry}

For identification of elastic fibres, the Weigert's ResorcinFuchsin technique with oxidation was used [22].

\section{Immunohistochemistry}

Antigen retrieval and primary antibodies are shown in table $1 S$ in the online supplementary material. Details of the immunohistochemical techniques are described in the online supplementary material.

\section{Morphological analysis}

Two large (epithelial basement membrane perimeter $>6 \mathrm{~mm}$ ) airways and three small $(\leqslant 6 \mathrm{~mm})$ airways cut in a transverse section, and 10 peribronchiolar (the site of alveolar attachments) and 10 distal alveolar segments (alveolar septa positioned at least $1 \times 100$ field from any small airway border) were analysed for all subjects [23].

The airway walls were subdivided into the inner layer, comprising the region between the epithelium and the internal smooth muscle border, the smooth muscle layer and the outer layer, located between the external smooth muscle border and the external limit of the airway, i.e. the alveolar parenchyma (fig. $1 \mathrm{~S}$ in the online supplementary material).

In large airways, type-IV collagen and tenascin mainly stained the subepithelial region of the bronchial epithelial layer and the walls of blood vessels. To avoid including the type-IV collagen and tenascin present in blood vessels, we analysed only subepithelial areas in the large airways. These were defined as a region of $12 \mu \mathrm{m}$ below the epithelium. We further analysed the muscle layer of the large airways, the inner and muscle layer of small airways and the distal and peribronchiolar parenchyma. For the large airways, we measured 10 fields of the subepithelial area at a magnification of $400 \times$.

Fractional areas of each compartment were determined by image analysis, using the Image-Pro Plus 4.1 for Windows software (Media Cybernetics, Silver Spring, MD, USA). Measurements of positively stained areas were performed as previously described [24]. Staining intensity was analysed by mean colour density (weighted mean per biopsy) and presented as intensity value (white $=0$; black $=255$ ). Detailed information is described in the online supplementary material.

\section{Statistical analysis}

Statistical analysis was performed with the SPSS 15.0 software (SPSS, Chicago, IL, USA). Data are presented as mean \pm SD or median (interquartile range (IQR)), depending on data distribution. To compare data between NS, NOS and COPD groups a one-way ANOVA or Kruskal-Wallis test was used, as appropriate. Bonferroni adjustments were used for multiple analysis tests. We performed a full-factorial general linear model to assess the effects of group, sex, age and centre on the fractional areas of ECM components in different lung compartments; inner, muscle and outer layer were combined in large and small airways, and peribronchial/distal parenchyma were analysed together. The results of the general linear models are shown only for ECM components that were significantly different among groups in the univariate analyses. The complete data of general linear model analysis are presented in the online supplementary material [25].

The unpaired t-test or the Mann-Whitney test was used to compare differences between smokers and ex-smokers. Fractional areas of ECM components were compared in large versus small airways and in peribronchial versus distal parenchyma using 
paired t-tests. The association between morphological and clinical data was performed using Pearson's or Spearman's coefficient tests. A p-value of 0.05 was considered significant.

\section{RESULTS \\ Subjects}

The characteristics of the groups are presented in table 1 . The COPD group was similar to the NOS group with respect to age and smoking history, but, as expected, had lower lung function than the other two groups. The mean \pm SD of FEV1/FVC was $58.3 \pm 9.8 \%$ in the COPD subjects compared with $77.5 \pm 6.5 \%$ and $83.4 \pm 7.6 \%$ for the NOS and NS, respectively $(p \leqslant 0.0001)$. The FEV1/FVC ratio in the COPD patients was below the lower limit of normal (69.6 \pm 1.7$)$ [26]. Eight of the subjects with COPD and none of the subjects in the other two groups were receiving steroids at the time of surgery.

The NS individuals were significantly younger than NOS and COPD subjects $(p \leqslant 0.007)$. There were more females than males in the NS group.

\section{Morphometry}

Between 46-67 (mean 58) large airways and 137-157 small airways (mean 147) were measured depending on the protein studied. A total of 578 large airways and 1,465 small airways were measured. The mean perimeter of large airways of NS, NOS and COPD patients were $11.8 \pm 4.6 \mathrm{~mm}, 7.4 \pm 1.5 \mathrm{~mm}$ and $11.3 \pm 5.3 \mathrm{~mm}(\mathrm{p}=0.39)$, respectively. For small airways the perimeter was $1.9 \pm 0.8 \mathrm{~mm}, 2.1 \pm 1.0 \mathrm{~mm}$ and $2.0 \pm 1.4 \mathrm{~mm}$ in the NS, NOS and COPD patients $(p=0.64)$, respectively. The total length of peribronchial parenchyma analysed was $12.8 \mathrm{~mm}, 12.2 \mathrm{~mm}$ and $12.9 \mathrm{~mm}$ in the NS, NOS and COPD patients $(p=0.363)$, respectively. For distal parenchyma the total length in NS, NOS and COPD was $17.4 \mathrm{~mm}, 15.7 \mathrm{~mm}$ and $17.3 \mathrm{~mm}(\mathrm{p}=0.084)$, respectively.

\section{Elastic fibres}

The fractional area of elastic fibres was higher in NOS compared to COPD and NS groups in the inner layer $(\mathrm{p}<0.03)$, muscle layer $(\mathrm{p}<0.0001)$ and outer layer $(\mathrm{p}<0.001)$ of the large and small airways, as well as peribronchiolar

\begin{tabular}{lccc}
\hline TABLE 1 & Characteristics of the study groups \\
& Nonsmokers & $\begin{array}{c}\text { Non-obstructed } \\
\text { smokers }\end{array}$ & COPD \\
& \multicolumn{3}{c}{} \\
\hline Subjects & 16 & 26 & 26 \\
Age yrs & $52 \pm 13^{\#}$ & $62 \pm 8$ & $67 \pm 9$ \\
Male/female & $4 / 12$ & $19 / 7$ & $24 / 2$ \\
Non-/ex-/current smoker & $16 / 0 / 0$ & $0 / 16 / 10$ & $0 / 12 / 14$ \\
Pack-yrs & & $60 \pm 34$ & $67 \pm 33$ \\
FEV $\%$ pred & $108.3 \pm 16.8$ & $97.2 \pm 11.4$ & $65.4 \pm 13.8^{*}$ \\
FEV 1 /FVC \% & $83.4 \pm 7.6$ & $77.5 \pm 6.5$ & $58.3 \pm 9.8^{*}$ \\
\hline
\end{tabular}

Data are presented as $\mathrm{n}$ or mean $\pm \mathrm{SD}$. COPD: chronic obstructive pulmonary disease; FEV1: forced expiratory volume in $1 \mathrm{~s}$; \% pred: \% predicted; FVC: forced vital capacity. ${ }^{\#}: p \leqslant 0.007$, significant difference of nonsmoker controls compared with the other two groups; ${ }^{\bullet}: p \leqslant 0.0001$, significant difference of COPD compared with other two groups. $(p<0.004)$ and distal parenchyma $(p<0.02)$. There were no significant differences between NS and COPD (fig. 1). Data are presented in table 2 .

There was a significant effect of group and centre in the large airways ( $p=0.051$ and $p=0.017$, respectively) and in the small airways ( $p=0.001$ and $p=0.038$, respectively) but not of age and sex. There were significant effects of group $(p=0.001)$ and sex $(p=0.012)$, but not of centre and age in the parenchyma (table $2 \mathrm{~S}$ online supplementary material).

\section{Immunohistochemical analysis}

Immunoreactivity of ECM proteins showed similar patterns of staining in the lung tissue of COPD patients, NOS and NS. The complete immunohistochemical data are presented in table 2.

\section{Type-I collagen}

The fractional area of type-I collagen in the inner layer of large airways and in the inner layer and muscle layer of small airways was lower in COPD patients when compared with NS $(\mathrm{p}=0.01, \mathrm{p}=0.004$ and $\mathrm{p}=0.03$, respectively). In the outer layer of small airways, type-I collagen was lower in COPD patients and in NOS when compared to NS controls $(\mathrm{p} \leqslant 0.01)$ (fig. 2).

There were no significant effects of group, centre, age and sex on large and small airways when all layers were combined (table 3S online supplementary material).

\section{Type-III and -IV collagen}

There were no differences among COPD, NOS and NS in large or small airways and peribronchial/distal parenchyma. Results from the immunohistochemical analyses are described in table 2 and the general linear model is described in tables $4 S$ and $5 S$ in the online supplementary material.

\section{Versican}

Versican fractional area was lower only in the distal parenchyma of the COPD patients compared with that seen in NS $(\mathrm{p}<0.05)$ (fig. 3). There were no differences among groups for versican fractional areas in large airways, small airways and in the peribronchiolar parenchyma.

There were no significant effects of group, centre, age and sex at a parechymal level (table $6 \mathrm{~S}$ online supplementary material).

\section{Decorin, biglycan and lumican}

There were no differences among COPD, NOS and NS in any of the large or small airway layers or peribronchial/distal parenchyma. Results from the immunohistochemical analyses are described in table 2 and the general linear model is described in tables 7S, 8S and 9S in the online supplementary material.

\section{Fibronectin}

Higher fibronectin fractional area was observed in the inner layer, muscle layer and outer layer of small airways of the COPD group compared with the NS and NOS groups $(\mathrm{p}<0.02$, $\mathrm{p}<0.05$ and $\mathrm{p}<0.04$, respectively) (fig. 4). In large airways and lung parenchyma there was no difference in fibronectin fractional area among groups.

There were no significant effects of group, centre, age and sex on small airway level (table $10 \mathrm{~S}$ online supplementary material). 

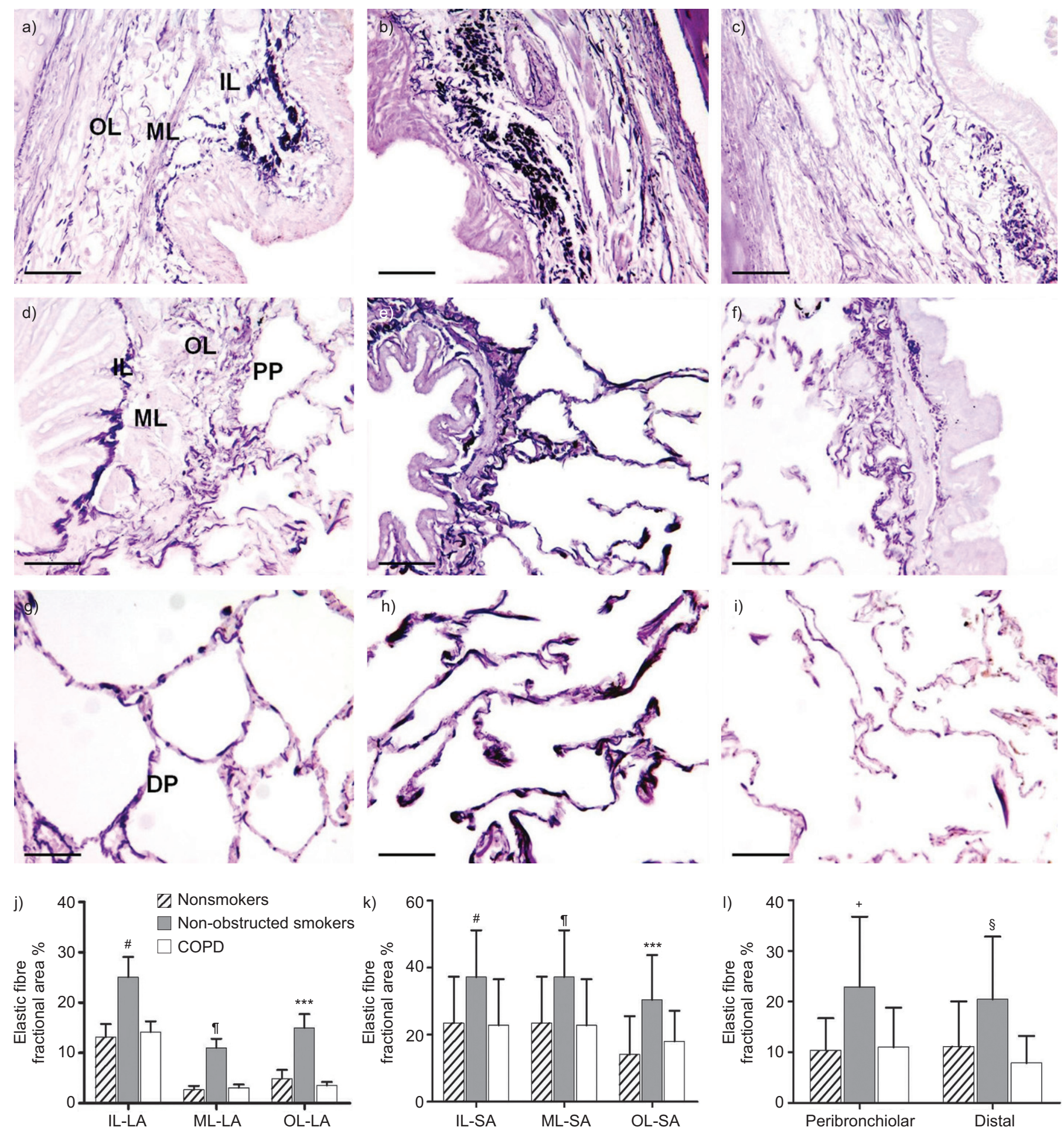

FIGURE 1. Elastic fibre fractional areas in a-c) large airways (LA), d-f) small airways (SA) and peribronchiolar parenchyma (PP), and g-i) distal parenchyma (DP) of nonsmokers ( $\mathrm{a}, \mathrm{d}$ and $\mathrm{g}$ ), non-obstructed smokers ( $\mathrm{b}, \mathrm{e}$ and $\mathrm{h}$ ) and chronic obstructive pulmonary disease (COPD) subjects $(\mathrm{c}, \mathrm{f}$ and $\mathrm{i})$. Scale bars $=50 \mu \mathrm{m}$. $j-\mathrm{l}) \mathrm{Fractional}$ areas of elastic fibres in the LA, SA, PP and DP. IL: inner layer; ML: muscle layer; OL: outer layer. Data are presented as mean \pm SD. ${ }^{* \star *}: p<0.001 ;{ }^{*}: p<0.03 ;{ }^{~}: p<0.0001$; ${ }^{+}: \mathrm{p}<0.004 ;{ }^{5}: \mathrm{p}<0.02$, in relation to nonsmokers and COPD subjects.

\section{Tenascin}

The fractional area of tenascin in the subepithelial area of large airways and in the inner layer of small airways was higher in the COPD group when compared with NS controls $(p<0.02$ versus $p<0.01)$ (fig. 5$)$. There were no differences among groups for tenascin fractional areas in muscle layer of large or small airways, or in the lung parenchyma. 
TABLE 2 Fractional areas ${ }^{\#}$ of extracellular matrix components in the airways and parenchyma of nonsmokers (NS), nonobstructed smokers (NOS) and chronic obstructive pulmonary disease (COPD) patients

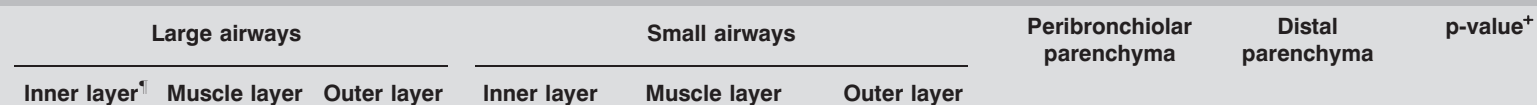

\begin{tabular}{|c|c|c|c|c|c|c|c|c|c|}
\hline $\begin{array}{l}\text { NS } \\
\text { NOS } \\
\text { COPD } \\
\text { p-value }^{\text {s }}\end{array}$ & $\begin{array}{c}13.2 \pm 7.8 \\
25.1 \pm 11.4 \\
14.2 \pm 7.8 \\
<0.03^{\S \S}\end{array}$ & $\begin{array}{c}2.7 \pm 2.3 \\
11 \pm 5.2 \\
3.1 \pm 2.5 \\
<0.0001^{\S \S}\end{array}$ & $\begin{array}{r}4.9 \pm 5.3 \\
15 \pm 7.8 \\
3.5 \pm 2.6 \\
<0.001^{15}\end{array}$ & $\begin{array}{c}23.5 \pm 13.7^{f} \\
37.2 \pm 13.9^{f} \\
22.8 \pm 13.7 \\
<0.03^{\S \S}\end{array}$ & $\begin{array}{c}5.1 \pm 4.1^{\# \#} \\
18.3 \pm 12.6 \\
6.6 \pm 5.7^{\# \#} \\
<0.0001^{\S \S}\end{array}$ & $\begin{array}{c}14.1 \pm 11.4^{\varphi} \\
30.4 \pm 13.3^{\bullet \bullet} \\
18.1 \pm 9.1^{\%} \\
<0.001^{\S \S}\end{array}$ & $\begin{array}{c}10.3 \pm 6.3 \\
22.9 \pm 13.9 \\
11 \pm 7.8 \\
<0.004^{\S \S}\end{array}$ & $\begin{array}{c}11.1 \pm 8.8 \\
20.5 \pm 12.4 \\
7.9 \pm 5.3^{++} \\
<0.02^{\$ \$}\end{array}$ & $\begin{array}{l}\leqslant 0.042 \\
\leqslant 0.028 \\
\leqslant 0.025\end{array}$ \\
\hline \multicolumn{10}{|c|}{ Type-I collagen } \\
\hline NS & $14.7 \pm 11.6$ & $9.5(18)$ & $19 \pm 9.8$ & $25.4 \pm 17.7^{f}$ & $8.6(14)$ & $34.1 \pm 15.8^{\circ}$ & $8 \pm 4.7$ & $6.7 \pm 4.4$ & $\leqslant 0.05$ \\
\hline NOS & $7.8 \pm 6.3$ & $2(7)$ & $11 \pm 7.7$ & $17.4 \pm 12^{f}$ & $4.3(10)$ & $21.7 \pm 11.6^{\circ}$ & $7.1 \pm 6$ & $5.7 \pm 4.6$ & $\leqslant 0.027$ \\
\hline \multicolumn{10}{|c|}{ Type-III collagen } \\
\hline NS & $12.3 \pm 10.8$ & $2.6(14)$ & $18.7 \pm 14.5$ & $8.6(13)$ & $1.9(7)$ & $14.4 \pm 12$ & $0.8(3)$ & $1(4)$ & 0.85 \\
\hline NOS & $10.9 \pm 9.1$ & 1 (2) & $11.9 \pm 13.4$ & $8.6(20)$ & $2(3)$ & $9.9 \pm 7.6$ & $0.5(1)$ & $1.7(3)$ & 0.91 \\
\hline COPD & $13 \pm 15.8$ & $0.8(12)$ & $13 \pm 18.3$ & $3(12)$ & $1.3(6)$ & $10.5 \pm 12.1$ & $0.4(4)$ & $1.6(6)^{++}$ & 0.034 \\
\hline$p$-value ${ }^{\S}$ & 0.904 & 0.678 & 0.547 & 0.294 & 0.710 & 0.407 & 0.474 & 0.782 & \\
\hline$p$-value ${ }^{5}$ & 0.597 & 0.324 & & 0.326 & 0.36 & & 0.556 & 0.137 & \\
\hline \multicolumn{10}{|l|}{ Versican } \\
\hline $\begin{array}{l}\text { NS } \\
\text { NOS } \\
\text { COPD } \\
\text { p-value }^{\text {s }}\end{array}$ & $\begin{array}{r}25.9 \pm 16.9 \\
27 \pm 20.7 \\
38.2 \pm 18.3 \\
0.154\end{array}$ & $\begin{array}{c}7.8 \pm 8.6 \\
14.3 \pm 21.6 \\
22.7 \pm 20.6 \\
0.147\end{array}$ & $\begin{array}{c}9.7 \pm 6.8 \\
21.1 \pm 17.9 \\
20.9 \pm 14.4 \\
0.134\end{array}$ & $\begin{array}{c}38.6 \pm 22 \\
36.1 \pm 21.1 \\
48.5 \pm 16.7 \\
0.094\end{array}$ & $\begin{array}{c}17.6 \pm 20.3 \\
13.9 \pm 12.8 \\
21.5 \pm 14.1 \\
0.236\end{array}$ & $\begin{array}{c}25.1 \pm 16^{\varphi} \\
26.1 \pm 16.9 \\
34.6 \pm 18.2^{\bullet} \\
0.155\end{array}$ & $\begin{array}{c}23.3 \pm 17.5 \\
17.1 \pm 14.8 \\
20.8 \pm 13.9 \\
0.467\end{array}$ & $\begin{array}{c}22.2 \pm 15.5 \\
13.9 \pm 13.5 \\
10.9 \pm 8^{++} \\
<0.05^{f f}\end{array}$ & $\begin{array}{c}0.004 \\
0.96 \\
\leqslant 0.026\end{array}$ \\
\hline \multicolumn{10}{|l|}{ Decorin } \\
\hline $\begin{array}{l}\text { NS } \\
\text { NOS } \\
\text { COPD } \\
\text { p-value }^{\S}\end{array}$ & $\begin{array}{c}11.6 \pm 13.1 \\
22.5 \pm 17.3 \\
15.1 \pm 18.2 \\
0.296\end{array}$ & $\begin{array}{c}7.2 \pm 7.4 \\
9.8 \pm 8.3 \\
9 \pm 9.6 \\
0.782\end{array}$ & $\begin{array}{c}19.3 \pm 14.9 \\
24.3 \pm 17.3 \\
18.7 \pm 18.8 \\
0.674\end{array}$ & $\begin{array}{r}15 \pm 14.1 \\
21.2 \pm 19.1 \\
22.8 \pm 20.6 \\
0.442\end{array}$ & $\begin{array}{c}6.6(10) \\
9(21) \\
7.3(15) \\
0.286\end{array}$ & $\begin{array}{c}17.9 \pm 13.4 \\
20.1 \pm 15.1 \\
18.6 \pm 15 \\
0.882\end{array}$ & $\begin{array}{c}0.7(4) \\
2.8(7) \\
1(3) \\
0.444\end{array}$ & $\begin{array}{c}4.4(10)^{++} \\
1.6(3) \\
1.3(2) \\
0.102\end{array}$ & $\begin{array}{l}0.021 \\
0.59 \\
0.92\end{array}$ \\
\hline \multicolumn{10}{|l|}{ Biglycan } \\
\hline \multicolumn{10}{|c|}{ Fibronectin } \\
\hline $\begin{array}{l}\text { NS } \\
\text { NOS } \\
\text { COPD } \\
\text { p-value }^{\S}\end{array}$ & $\begin{array}{c}9.0 \pm 6.6 \\
11.4 \pm 10.8 \\
18.3 \pm 14.1 \\
0.136\end{array}$ & $\begin{array}{c}3.2 \pm 3.0 \\
5.6 \pm 7.4 \\
9.6 \pm 7.4 \\
0.074\end{array}$ & $\begin{array}{c}8.4 \pm 5.9 \\
16.3 \pm 16.9 \\
17.2 \pm 12.3 \\
0.284\end{array}$ & $\begin{array}{c}6.6 \pm 5.5 \\
13.4 \pm 12.5 \\
24.6 \pm 15.7 \\
<0.02\end{array}$ & $\begin{array}{r}5.3 \pm 5.7 \\
6.1 \pm 7.2 \\
11.3 \pm 9.6 \\
<0.05\end{array}$ & $\begin{array}{l}11.1 \pm 8.6 \\
16.6 \pm 12.7 \\
26.3 \pm 14.5^{\circ} \\
<0.04\end{array}$ & $\begin{array}{c}20 \pm 12.1 \\
24.8 \pm 18.8 \\
29.8 \pm 15.2 \\
0.240\end{array}$ & $\begin{array}{c}26.5 \pm 9.9 \\
28.1 \pm 16.4 \\
25.7 \pm 14.8^{++} \\
0.862\end{array}$ & $\begin{array}{l}0.84 \\
0.96 \\
<0.04\end{array}$ \\
\hline \multicolumn{10}{|l|}{ Tenascin } \\
\hline NS & $24.4 \pm 25.8$ & $6.6(18)$ & & $0.45(2)$ & $15.3 \pm 14.9$ & & $3.7(12)$ & $12.1 \pm 8.2$ & 0.19 \\
\hline NOS & $44.9 \pm 31.5$ & $4.6(13)$ & & $13.9(4)$ & $8.5 \pm 9.5$ & & $2.6(10)$ & $11 \pm 10.7^{++}$ & $\leqslant 0.006$ \\
\hline COPD & $56.2 \pm 23.4$ & $8.6(8)$ & & $25.6(11)$ & $17.8 \pm 16.5$ & & $4.9(10)$ & $10.2 \pm 7.4$ & 0.33 \\
\hline$p$-value ${ }^{\S}$ & $<0.02^{f f}$ & 0.451 & & $<0.01^{f f}$ & 0.075 & & 0.646 & 0.853 & \\
\hline
\end{tabular}

Data are presented as mean \pm SD or median (interquartile range), unless otherwise stated. * : expressed as a percentage of the total area in each compartment; ": type-IV collagen and tenascin quantification were performed in the subepithelial area of the inner layer; ${ }^{+}:$comparison between compartments of large airways with their respective compartment in small airways and between peribronchial and distal parenchyma (the p-value corresponds to the highest value found in the five analyses); ${ }^{5}:$ comparison among the patient groups; $f:$ small

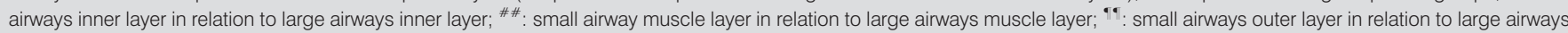

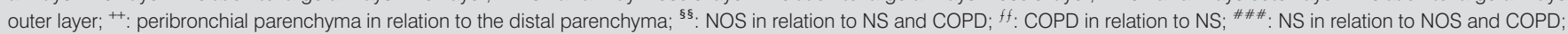
\%": COPD in relation to NS and NOS. 


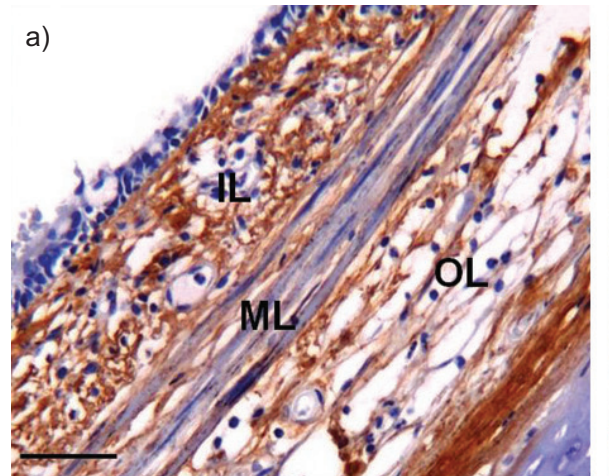

d)
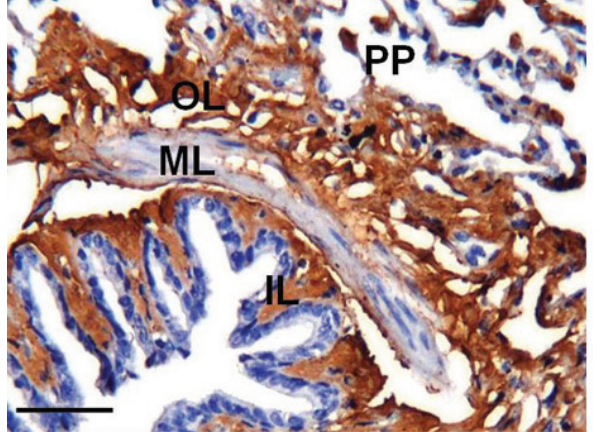

Q)
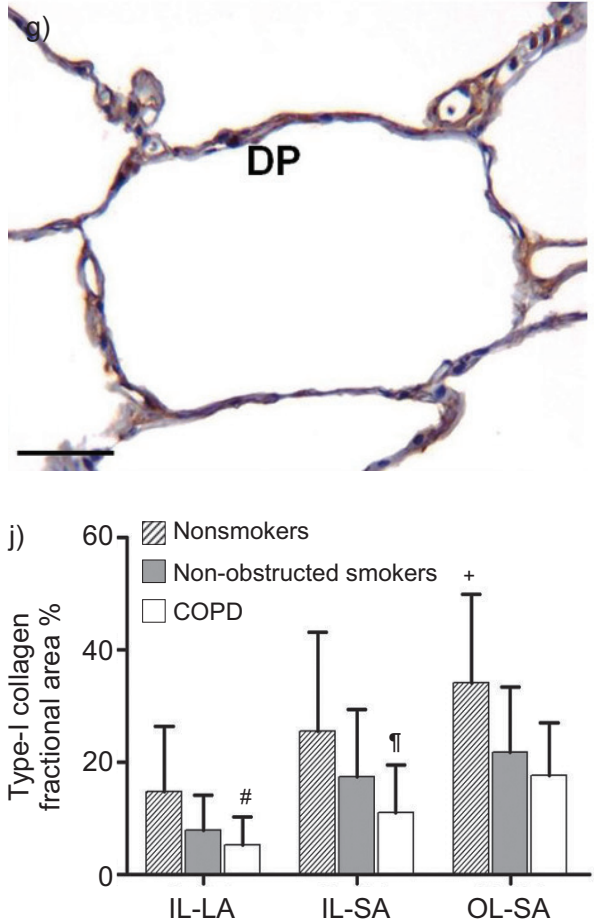
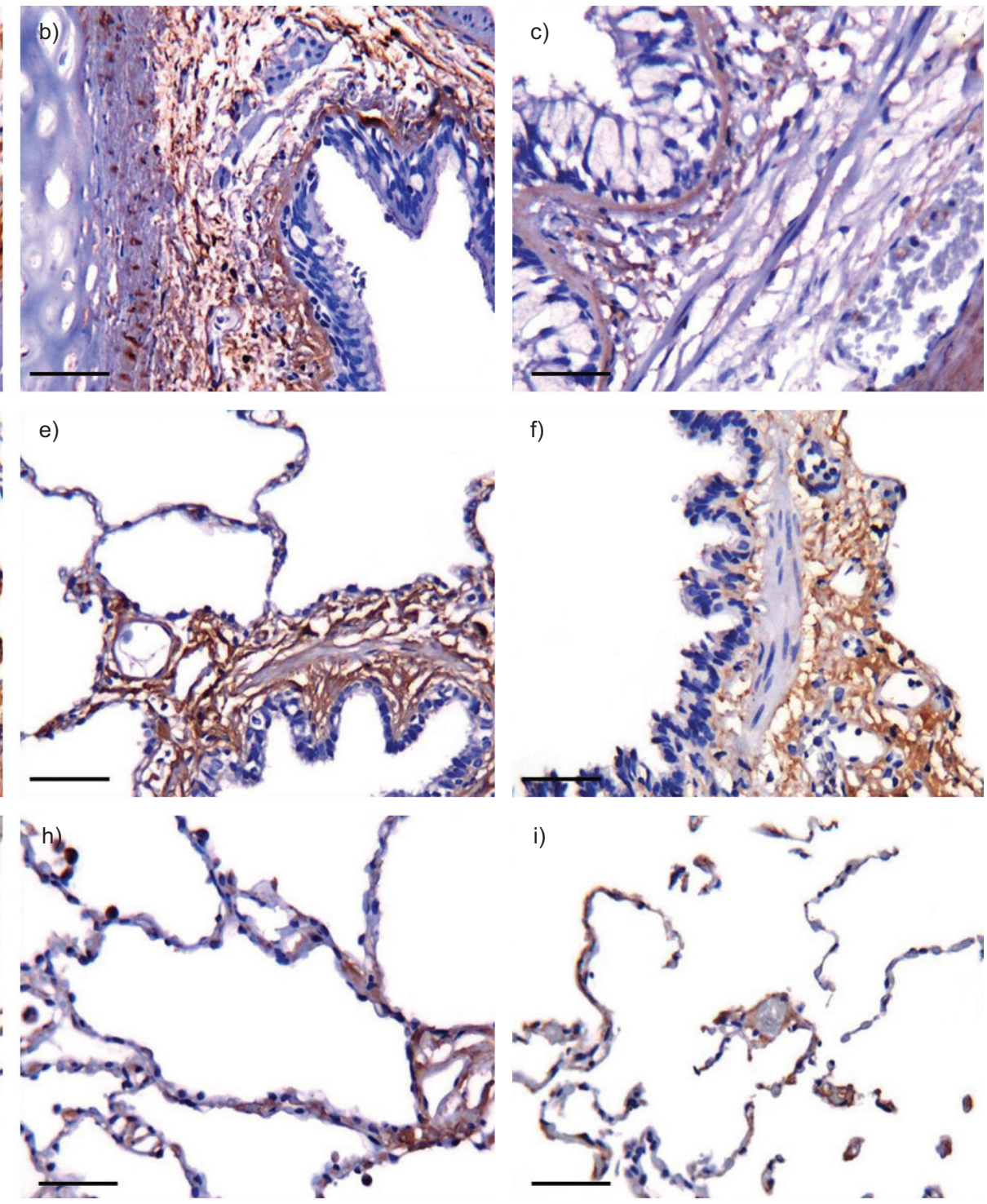

f)
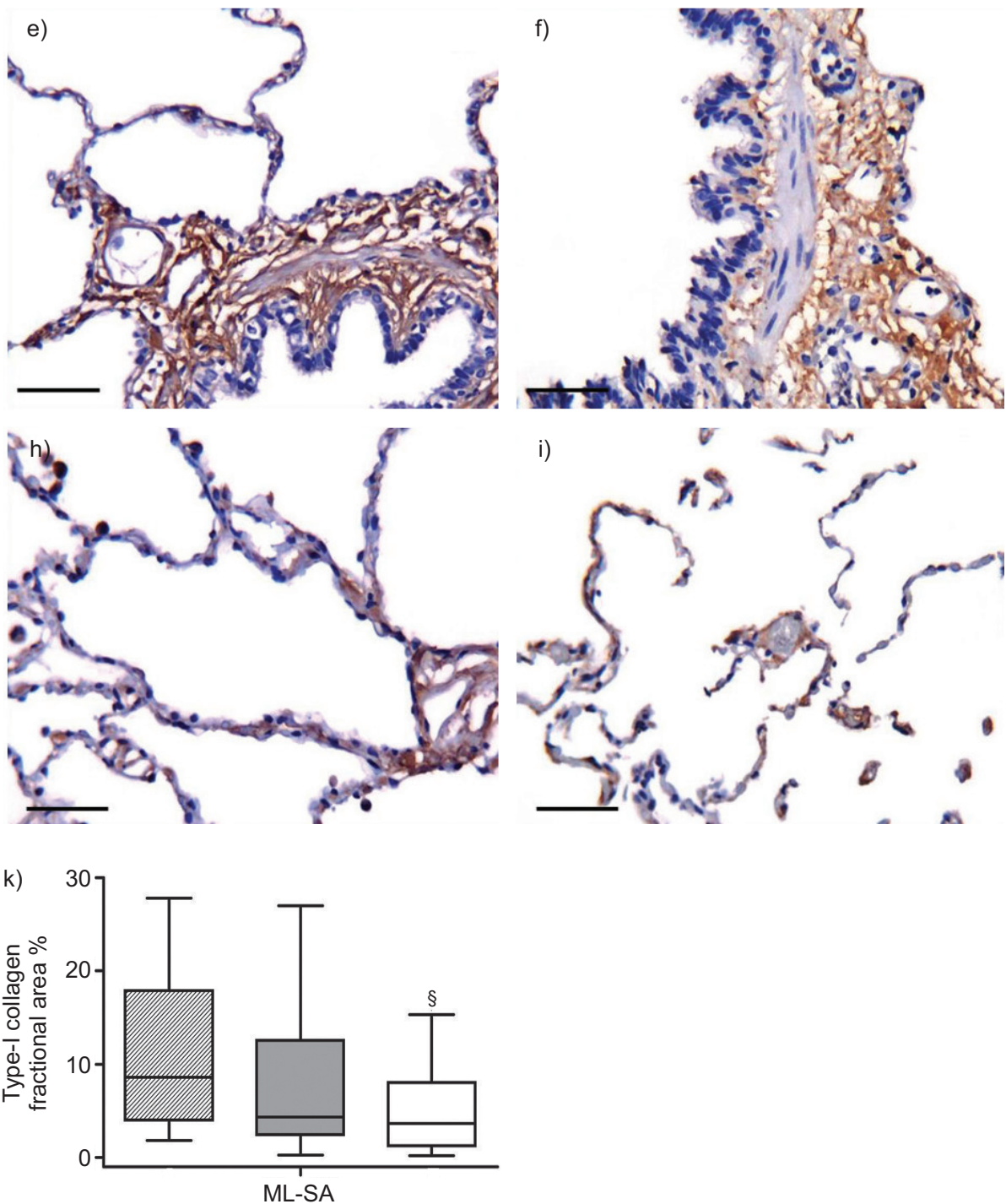

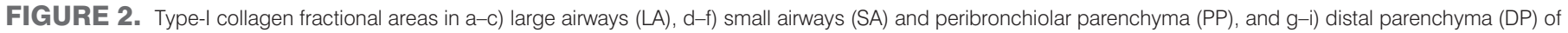

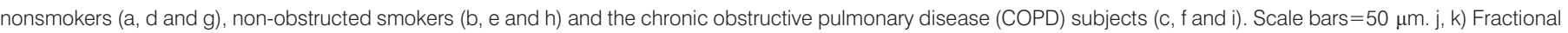

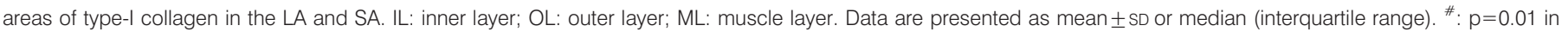

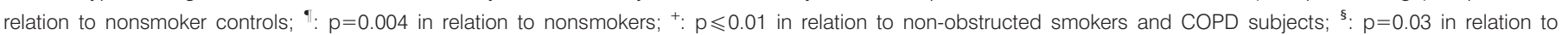
nonsmokers. 

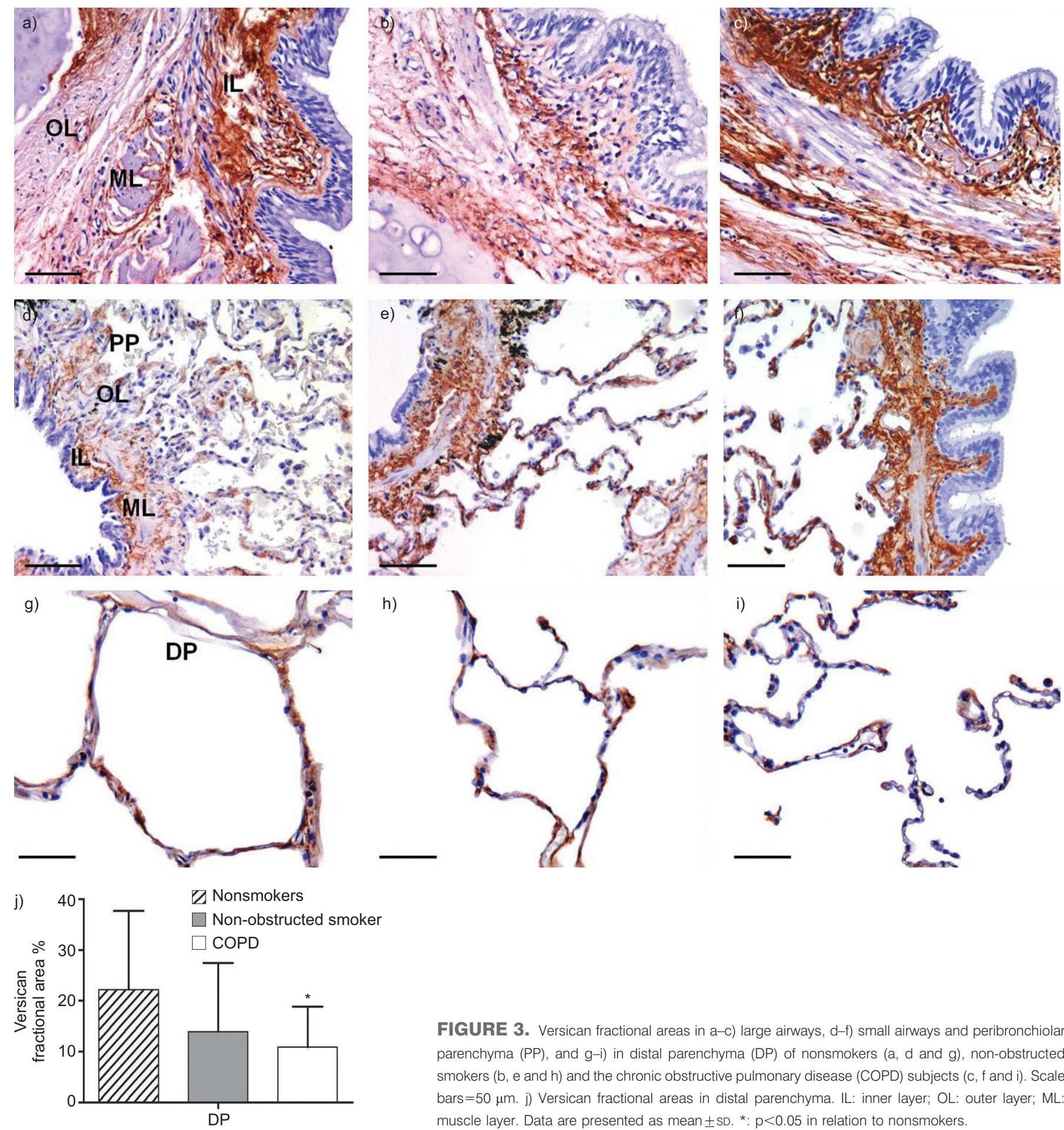

FIGURE 3. Versican fractional areas in $a-c)$ large airways, $d-f$ ) small airways and peribronchiolar parenchyma (PP), and $\mathrm{g}-\mathrm{i}$ ) in distal parenchyma (DP) of nonsmokers ( $\mathrm{a}, \mathrm{d}$ and $\mathrm{g}$ ), non-obstructed smokers (b, e and $h$ ) and the chronic obstructive pulmonary disease (COPD) subjects (c, f and i). Scale bars $=50 \mu \mathrm{m}$. j) Versican fractional areas in distal parenchyma. IL: inner layer; OL: outer layer; ML: muscle layer. Data are presented as mean \pm SD. *: $p<0.05$ in relation to nonsmokers.

There were no significant effects of group, centre, age and sex on airways levels (table 11S online supplementary material).

\section{Large versus small airways/peribronchial versus distal parenchyma}

Differences between ECM fractional areas in large versus small airways and peribronchiolar and distal alveolar septa are presented in table 2 .

\section{Mean colour density}

The results of mean colour density of ECM proteins were similar to those shown in the fractional area (data not shown).

\section{Clinical-morphological correlations}

Within the COPD group, inverse correlations were found between FEV1 \% pred and elastic fibre fractional area of the outer layer of large airways $(r=-0.66, p=0.009)$ and the muscle 

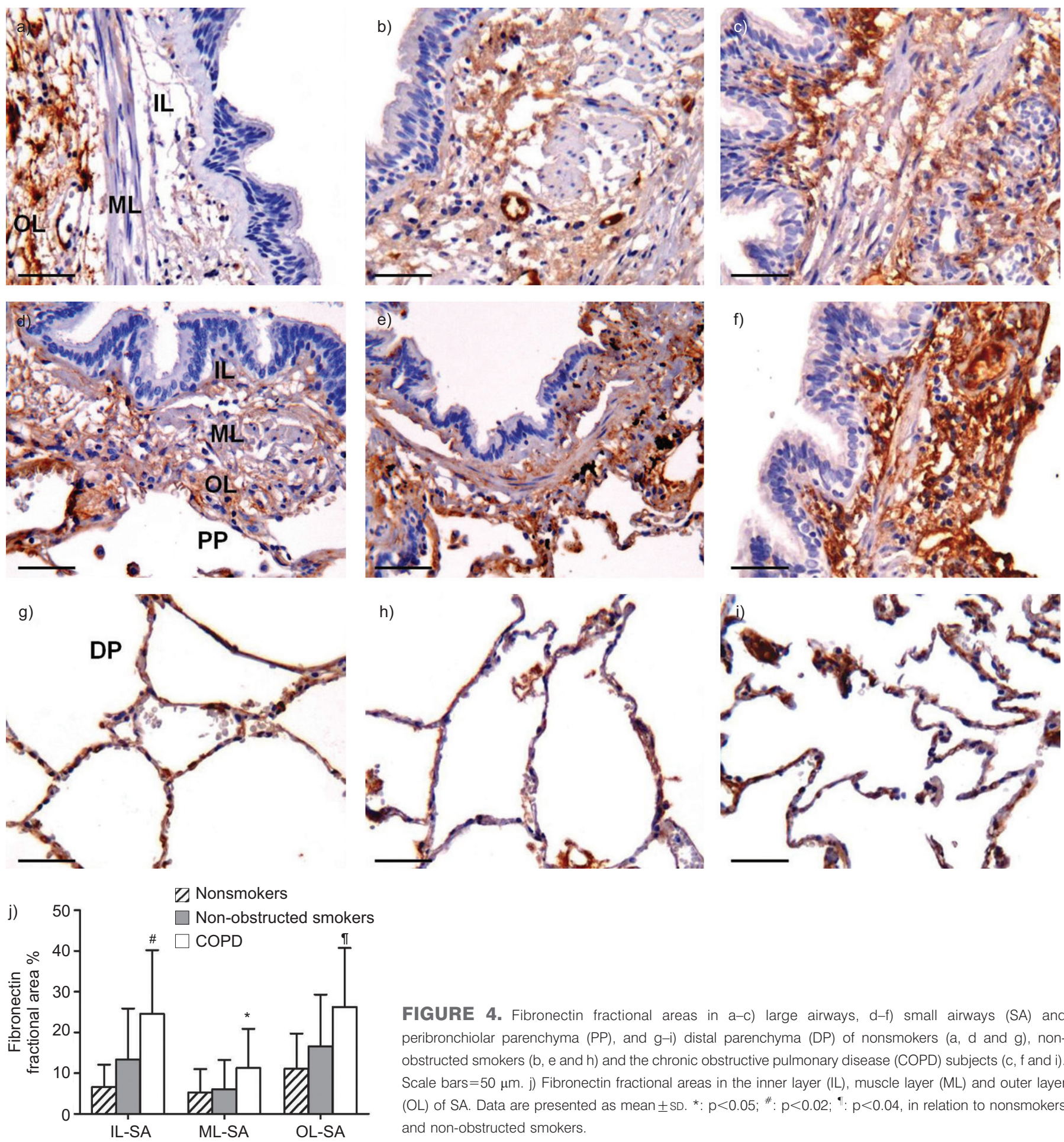

FIGURE 4. Fibronectin fractional areas in a-c) large airways, $d-f$ ) small airways (SA) and peribronchiolar parenchyma (PP), and g-i) distal parenchyma (DP) of nonsmokers (a, d and g), nonobstructed smokers (b, e and $\mathrm{h}$ ) and the chronic obstructive pulmonary disease (COPD) subjects (c, $\mathrm{f}$ and $\mathrm{i}$ ). Scale bars $=50 \mu \mathrm{m}$. j) Fibronectin fractional areas in the inner layer (IL), muscle layer (ML) and outer layer $(\mathrm{OL})$ of SA. Data are presented as mean \pm SD. ${ }^{*}: p<0.05$; ${ }^{\#}: p<0.02$; ${ }^{\top}: p<0.04$, in relation to nonsmokers and non-obstructed smokers.

layer $(\mathrm{r}=-0.48, \mathrm{p}=0.03)$ of small airways; and between FEV1/ FVC and fibronectin fractional area in the muscle layer of small airways ( $\mathrm{r}=-0.39 \mathrm{p}=0.05) \quad$ (fig. $2 \mathrm{~S}$ online supplementary material).

When only the NOS group was analysed, age was related to the elastic fibre fractional area of the outer layer of large airways $(r=0.74, p=0.038)$. Inverse correlation was found between pack-yrs and elastic fibre fractional area of distal parenchyma $(r=-0.59, p=0.026)$. Inverse correlations were also seen in fibronectin fractional areas between FEV1 \% pred and the inner layer $(r=-0.50, p=0.018)$ and outer layer $(r=-0.47$, $\mathrm{p}=0.027$ ) of small airways (fig. $3 \mathrm{~S}$ online supplementary material). There were no correlations between clinical parameters and ECM composition in the NS group.

Within COPD patients, significant correlations were seen in elastic fibre fractional areas between small airways and lung 

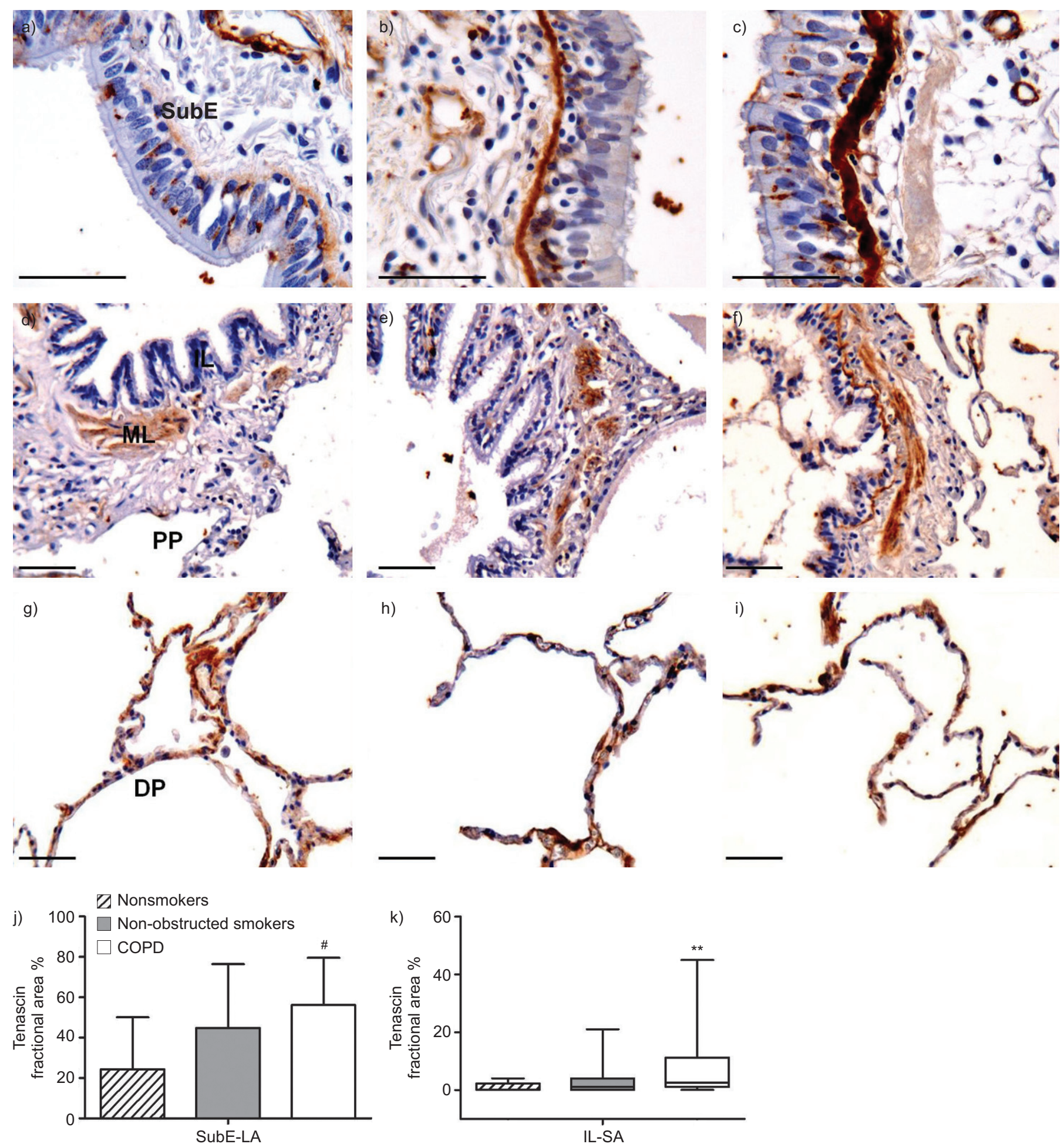

FIGURE 5. Tenascin fractional areas in a-c) large airways (LA), d-f) small airways (SA) and peribronchiolar parenchyma (PP), and g-i) distal parenchyma (DP) of nonsmokers ( $\mathrm{a}, \mathrm{d}$ and $\mathrm{g}$ ), non-obstructed smokers ( $\mathrm{b}$, e and $\mathrm{h}$ ) and chronic obstructive pulmonary disease (COPD) subjects (c, f and i). Scale bars=50 $\mu \mathrm{m}$. j, k) Tenascin fractional areas in the subepithelai region (SubE), and the inner layer (IL) of (LA) and SA. ML: muscle layer. Data are presented as mean \pm SD. ${ }^{* *}$ : $p<0.01$; ${ }^{*}: p<0.02$, in relation to nonsmokers.

parenchyma $(\mathrm{r}=0.77, \mathrm{p}<0.0001)$. Positive correlations were observed in versican fractional areas between small airways and large airways $(\mathrm{r}=0.61, \mathrm{p}<0.02)$, and between small airways and lung parenchyma $(\mathrm{r}=0.72, \mathrm{p}<0.0001)$. We also found significant correlations in fibronectin fractional areas between small airways and lung parenchyma $(\mathrm{r}=0.72$, $\mathrm{p}<0.0001)$. Tenascin fractional areas in large airways correlated positively with the lung parenchyma $(\mathrm{r}=0.61, \mathrm{p}<0.02)$. 


\section{Current versus ex-smokers}

Median (IQR) duration of smoking cessation in ex-smokers was $6.0(2.25-10)$ yrs. There were no significant differences in ECM composition when current smokers were compared with ex-smokers, irrespective of obstruction (data not shown).

\section{DISCUSSION}

In this study we described changes in the composition of the ECM in large and small airways and alveolar parenchyma of patients with COPD compared with smoking or nonsmoking subjects without airflow obstruction. Higher fractional areas of elastic fibres were found in NOS compared with COPD patients and NS subjects. The expression of type-I collagen in the large and small airways and of versican fractional area in distal parenchyma was lower in COPD compared with NS. The fractional areas of the fibronectin and tenascin were higher in small and large (tenascin) airways of patients with COPD. These results were not influenced by smoking status or packyrs. Our results indicate that COPD features complex alterations in ECM composition in both large and small airways.

Damage of elastic fibres is a classical concept in the pathophysiology of COPD, which may result from the elastase/antielastase imbalance caused by cigarette smoking [27]. BLACK et al. [14] demonstrated less elastic fibres in the distal lung of COPD patients compared with smokers. Our findings complement this study, since we demonstrated lower elastic fibre fractional area in the large and small airways and in the lung parenchyma of COPD patients compared with NOS. Unexpectedly, when COPD patients were compared with NS, no differences were found.

How can we interpret these findings? DesLEE et al. [28] demonstrated increased elastin gene expression in severe COPD patients without a significant increase in the elastic fibres density or in the desmosine content. These authors suggested that severe COPD patients might have a nonefficient repair of elastic fibres. Our findings are in line with these observations, and suggest that smokers without COPD may be able to increase elastin expression as a response to the smoke-related injury, whereas such an increase may not occur in COPD. Interestingly, CANTOR et al. [29] have shown that 3 months of exposure to cigarette in mice causes elastic fibre proliferation in the airways. Humans have an inability to adequately synthesise elastin in tissues beyond childhood [30]. We have not assessed the integrity/quality of elastic fibres in this study, but elastic fibre breakdown occurs both in NOS and COPD patients [31, 32]. Therefore, it is likely that in smokers elastic fibres may also not be fully functional.

The current inverse associations between airway elastic fibres content and FEV1 amongst patients with COPD are in line with previous data [28]. These data suggest that airflow limitation and/or airway collapse are less common in patients with the lowest airway elastic fibres content. One may speculate that lowered elastic fibres content reduces airway wall compliance thereby increasing airway wall stiffness, which indeed has been observed in COPD [33] and even in asthma [34]. Hence, in the presence of COPD lowered airway elastic fibres content may even represent a protective mechanism against airflow limitation. Notably, in a combined analysis of COPD patients and asymptomatic smokers, airway elastic fibres content have been reported to be positively associated with spirometric values [14]. The latter was confirmed by including asymptomatic smokers in the current analysis (data not shown) and suggests that loss of airway elastic fibres in absence of COPD may also be detrimental for lung function, similar to loss of parenchymal elastic fibres as occurs in emphysema [9].

The results of collagen studies in COPD are conflicting. While some studies demonstrated increased collagen in alveoli of COPD patients $[12,35]$, others showed no difference between COPD and controls [11]. Few studies have focused on collagen subtypes in the airways. HoGg et al. [36] demonstrated a decrease in total collagen in bronchioles of severe COPD associated with a decrease in type-I/-III collagen ratio. GossELINK et al. [37] found a decreased expression of collagen type-I, $\alpha 1$ (COL1A1) and collagen type-III, $\alpha 1$ (COL3A1) genes associated with the decline in FEV1 in lung tissue surrounding the bronchioles and in the small airways, respectively. They suggested that the thickening of small airways could not be associated to the expression of genes related to fibrogenesis.

In this study, we demonstrated less type-I collagen fractional area in COPD patients. We speculate that the loss of structural proteins leads to a reduction of stiffness of the airways, making them more susceptible to external forces applied during normal expiration, favouring collapse. In addition, we observed lower type-I collagen content in the outer layer of small airways of NOS compared with NS. It is possible that type-I collagen structural alterations at this level contribute to the airway-parenchyma uncoupling described in smokers without COPD [38].

Versican is an abundant member of the hyalectan family of the proteoglycans in the lungs [18]. We describe smaller versican fractional area in the distal parenchyma of COPD patients compared with NS. Conversely, in mild/moderate COPD patients, MERRILEES et al. [10] demonstrated an increased versican staining (by semiquantitative analysis) in alveoli of COPD patients compared with smoking controls. The reason for these discrepant results is not clear, but can be associated with the different methods of analyses used in both studies.

Decorin, biglycan and lumican are small proteoglycans which interact with fibrillar collagens, participating in the maintenance of the extracellular milieu [39-41]. In vitro studies have indicated that fibroblasts from COPD patients present abnormal production of proteoglycans and altered expression of the transforming growth factor (TGF)- $\beta$ Smad pathway when exposed to cigarette smoke or different cytokines [42, 43]. In the present study, no differences were found in decorin, biglycan and lumican expression in mild/moderate COPD when compared with NOS and NS controls. VAN STRAATEN et al. [11] showed that decorin and biglycan staining were decreased in the peribronchiolar area in severe compared with mild emphysema patients. Later, NoORDHOEK et al. [44] demonstrated that decorin production by fibroblast cultures isolated from lung tissue of patients with severe emphysema is higher in a basal situation and is more significantly downregulated after stimulation with TGF- $\beta$ than the production by fibroblasts from patients with mild emphysema. Taken together with our results, alterations in proteoglycans seem to be more pronounced in the severe forms of COPD.

Tenascin and fibronectin play important morphoregulatory roles during lung development. In adult life, both proteins are 
altered after tissue injury and inflammation, regulating cell adhesion, migration and differentiation [7]. Previous studies have shown that tenascin expression in large airways was altered in COPD patients and in smokers [20,45]. Our data expand on these observations, showing higher tenascin expression in large and small airways of COPD patients. Fibronectin was also higher in COPD patients, mainly at the small airway level. Interestingly, tenascin and fibronectin induce matrix metalloproteinase expression and activity [7], contributing to the perpetuation of tissue injury. The inverse correlation of fibronectin with lung function in COPD patients reinforces these suppositions.

Our study has limitations. We lack a severe COPD group, which would have contributed to a more comprehensive description of the ECM composition in this disease. Another limitation was the younger age of the NS group, but multivariate analyses showed no significant effect of age in the data. Interestingly, an effect of centre was observed for several proteins, suggesting that ethnic/environmental factors might affect ECM composition in the lungs and contribute to different phenotypes in COPD.

Although pulmonary tissue far from the tumour was analysed, we cannot exclude that the observed changes in ECM were affected by malignancy. As all patients had malignancies, it is unlikely that an interaction would occur only in the COPD group. Some of the COPD patients did not have lung function assessed following bronchodilator; however, these older adults were or had been heavy smokers, and had no history of asthma, lung fibrosis or bronchiectasis.

Since bronchial biopsies from large airways are being used for research purposes in COPD [46], an important question is whether disease patterns are similar in the central versus distal lung. Similar patterns of ECM remodelling in large and small airways were observed for elastic fibres, type-I collagen and tenascin in COPD patients. However, more significant correlations in the pattern of ECM composition in COPD patients were found between small airways and parenchyma.

In summary, we showed that alterations of the major ECM elements, elastic fibres, collagens, versican, fibronectin and tenascin, are widespread in all lung compartments of mild/ moderate COPD patients. The altered ECM composition in COPD is likely to contribute to the persistent tissue injury and may have a role in the airflow obstruction characteristic of this disease.

\section{SUPPORT STATEMENT}

This study received support from the Coordenação de Aperfeiçoamento de Pessoal de Nível Superior (CAPES), the Conselho Nacional de Desenvolvimento Científico e Tecnológico (CPNq; both Brasília, Brazil) and Laboratório de Investigação Médica 05 (LIM05-HCFMUSP; University of São Paulo Medical School, São Paulo, Brazil).

\section{STATEMENT OF INTEREST}

Statements of interest for P.S. Hiemstra, P.J. Sterk and K.F. Rabe can be found at www.erj.ersjournals.com/site/misc/statements.xhtml

\section{ACKNOWLEDGEMENTS}

We thank K.Y.M. Kimoto and the thoracic surgeons of the Thoracic Surgery Division at Hospital das Clfínicas (University of São Paulo
Medical School, São Paulo, Brazil) and A.C. Camargo Hospital (São Paulo), for their assistance in collecting the lung tissue. We also thank A. James (University of Western Australia, Crawley, Australia) for his constructive comments on this manuscript.

\section{REFERENCES}

1 Rabe KF, Hurd S, Anzueto A, et al. Global strategy for the diagnosis, management, and prevention of chronic obstructive pulmonary disease: GOLD executive summary. Am J Respir Crit Care Med 2007; 176: 532-555.

2 Buist AS, Vollmer WM, McBurnie MA. Worldwide burden of COPD in high- and low-income countries. Part I. The burden of obstructive lung disease (BOLD) initiative. Int J Tuberc Lung Dis 2008; 12: 703-708.

3 Menezes AM, Perez-Padilla R, Hallal PC, et al. Worldwide burden of COPD in high- and low-income countries. Part II. Burden of chronic obstructive lung disease in Latin America: the PLATINO study. Int J Tuberc Lung Dis 2008; 12: 709-712.

4 Hogg JC, Chu F, Utokaparch S, et al. The nature of small airway obstruction in chronic obstructive pulmonary disease. $N$ Engl J Med 2004; 24: 2645-2653.

5 Finkelstein R, Fraser RS, Ghezzo H, et al. Alveolar inflammation and its relation to emphysema in smokers. Am J Respir Crit Care Med 1995; 152: 1666-1672.

6 van der Geld YM, van Straaten JFM, Postma DS, et al. Role of proteoglycans in development and pathogenesis of emphysema. In: Garg HG, Roughley PJ, Hales CA, eds. Proteoglycans in Lung Disease. New York, Marcel Dekker, 2002; pp. 241-267.

7 Jones FS, Jones PL. The tenascin family of ECM glycoproteins: structure, function, and regulation during embryonic development and tissue remodelling. Dev Dyn 2000; 218: 235-259.

8 Wright RR. Elastic tissue of normal and emphysematous lungs: a tridimensional histologic study. Am J Pathol 1961; 39: 355-367.

9 Chrzanowski P, Keller S, Cerreta J, et al. Elastin content of normal and emphysematous lung parenchyma. Am J Med 1980; 69: 351-359.

10 Merrilees MJ, Ching PS, Beaumont B, et al. Changes in elastin, elastin binding protein and versican in alveoli in chronic obstructive pulmonary disease. Respir Res 2008; 9: 41.

11 van Straaten JF, Coers W, Noordhoek JA, et al. Proteoglycan changes in the extracellular matrix of lung tissue from patients with pulmonary emphysema. Mod Pathol 1999; 12: 697-705.

12 Vlahovic G, Russell ML, Mercer RR, et al. Cellular and connective tissue changes in alveolar septal walls in emphysema. Am J Respir Crit Care Med 1999; 160: 2086-2092.

13 Kranenburg AR, Willems-Widyastuti A, Moori WJ, et al. Enhanced bronchial expression of extracellular matrix proteins in chronic obstructive pulmonary disease. Am J Clin Pathol 2006; 126: 725-735.

14 Black PN, Ching PS, Beaumont B, et al. Changes in elastic fibres in the small airways and alveoli in COPD. Eur Respir J 2008; 31: 998-1004.

15 Suki B, Bates JH. Extracellular matrix mechanics in lung parenchymal diseases. Respir Physiol Neurobiol 2008; 163: 33-43.

16 Dunsmore SE. Treatment of COPD: a matrix perspective. Int J Chron Obstruct Pulmon Dis 2008; 3: 113-122.

17 Hardingham TE, Fosang AJ. Proteoglycans: many forms and many functions. FASEB J 1992; 6: 861-870.

18 Iozzo RV. Matrix proteoglycans: from molecular design to cellular function. Ann Rev Biochem 1998; 67: 609-652.

19 Lambropoulou M, Limberis V, Koutlaki N, et al. Differential expression of tenascin-C in the developing human lung: an immunohistochemical study. Clin Exp Med 2009; 9: 333-338.

20 Liesker JJ, Ten Hacken NH, Zeinstra-Smith M, et al. Reticular basement membrane in asthma and COPD: similar thickness, yet different composition. Int J Chron Obstruct Pulmon Dis 2009; 4: 127-135. 
21 Löfdahl M, Kaarteenaho R, Lappi-Blanco E, et al. Tenascin-C and alpha-smooth muscle actin positive cells are increased in the large airways in patients with COPD. Respir Res 2011; 12: 48.

22 Mauad T, Xavier ACG, Saldiva PHN, et al. Elastosis and fragmentation of fibres of the elastic system in fatal asthma. Am J Resp Crit Care Med 1999; 160: 968-975.

23 Mauad T, Silva LF, Santos MA, et al. Abnormal alveolar attachments with decreased elastic fibres content in distal lung in fatal asthma. Am J Respir Crit Care Med 2004; 170: 857-862.

24 Araujo BB, Dolhnikoff M, Silva LF, et al. Extracellular matrix components and regulators in the airway smooth muscle in asthma. Eur Respir J 2008; 32: 61-69.

25 James AL, Bai TR, Mauad T, et al. Airway smooth muscle thickness in asthma is related to severity but not duration of asthma. Eur Respir J 2009; 34: 1040-1045.

26 Pereira CA, Sato T, Rodrigues SC. Novos valores de referência para espirometria forçada em brasileiros adultos de raça branca [New reference values for forced spirometry in white adults in Brazil]. J Bras Pneumol 2007; 33: 397-406.

27 Barnes PJ, Shapiro SD, Pauwels RA. Chronic obstructive pulmonary disease: molecular and cellular mechanisms. Eur Respir J 2003; 22: 672-688.

28 Deslee G, Woods JC, Moore CM, et al. Elastin expression in very severe human COPD. Eur Respir J 2009; 34: 324-331.

29 Cantor JO, Cerreta JM, Ochoa M, et al. Therapeutic effects of hyaluronan on smoke-induced elastic fibres injury: does delayed treatment affect efficacy? Lung 2011; 189: 51-56.

30 Cock ML, Joyce BJ, Hooper SB, et al. Pulmonary elastin synthesis and deposition in developing and mature sheep: effects of intrauterine growth restriction. Exp Lung Res 2004; 30: 405-418.

31 Gottlieb DJ, Stone PJ, Sparrow D, et al. Urinary desmosine excretion in smokers with and without rapid decline of lung function: the Normative Aging Study. Am J Respir Crit Care Med 1996; 154: 1290-1295.

32 Boschetto P, Quintavalle S, Zeni E, et al. Association between markers of emphysema and more severe chronic obstructive pulmonary disease. Thorax 2006; 61: 1037-1042.

33 Baldi S, Dellacà R, Govoni L, et al. Airway distensibility and volume recruitment with lung inflation in COPD. J Appl Physiol 2010; 109: 1019-1026.
34 Brackel HJ, Pedersen OF, Mulder PG, et al. Central airways behave more stiffly during forced expiration in patients with asthma. Am J Respir Crit Care Med 2000; 162: 896-904.

35 Martin-Mosquero C, Peces-Barba G, Rubio ML, et al. Increased collagen deposition correlated with lung destruction in human emphysema. Histol Histopathol 2006; 21: 823-828.

36 Hogg JC, McDonough JE, Gosselink JV, et al. What drives the peripheral lung-remodelling process in chronic obstructive pulmonary disease? Proc Am Thorac Soc 2009; 6: 668-672.

37 Gosselink JV, Hayashi S, Elliott WM, et al. Differential expression of tissue repair genes in the pathogenesis of COPD. Am J Respir Crit Care Med 2010; 181: 1329-1335.

38 Saetta M, Ghezzo H, Kim WD, et al. Loss of alveolar attachments in smokers. A morphometric correlate of lung function impairment Am Rev Respir Dis 1985; 132: 894-900.

39 Roughley PJ, White RJ, Magny MC, et al. Non-proteoglycan forms of biglycan increase with age in human articular cartilage. Biochem J 1993; 295: 421-426.

40 Grover J, Chen XN, Korenberg JR, et al. The human lumican gene. Organization, chromosomal location, and expression in articular cartilage. J Biol Chem 1995; 270: 21942-21949.

41 Dolhnikoff M, Morin J, Roughley PJ, et al. Expression of lumican in human lungs. Am J Respir Cell Mol Biol 1998; 19: 582-587.

42 Hallgren O, Nihlberg K, Dahlbäck M, et al. Altered fibroblast proteoglycan production in COPD. Respir Res 2010; 11: 55.

43 Zandvoort A, Postma DS, Jonker MR, et al. Smad gene expression in pulmonary fibroblasts: indications for defective ECM repair in COPD. Respir Res 2008; 9: 83.

44 Noordhoek JA, Postma DS, Chong LL, et al. Different modulation of decorin production by lung fibroblasts from patients with mild and severe emphysema. COPD 2005; 2: 17-25.

45 Amin K, Ekberg-Jansson A, Löfdahl C-G, et al. Relationship between inflammatory cells and structural changes in the lungs of asymptomatic and never smokers: a biopsy study. Thorax 2003; 58 : 135-142.

46 Saetta M, Di Stefano A, Maestrelli P, et al. Activated T-lymphocytes and macrophages in bronchial mucosa of subjects with chronic bronchitis. Am Rev Respir Dis 1993; 147: 301-306. 